\title{
Efficacy of gelatin gel sheets in sustaining the release of basic fibroblast growth factor for murine skin defects
}

\section{$\operatorname{AUTHOR}(\mathrm{S}):$}

Sakamoto, Michiharu; Morimoto, Naoki; Ogino, Shuichi; Jinno, Chizuru; Taira, Tsuguyoshi; Suzuki, Shigehiko

\section{CITATION:}

Sakamoto, Michiharu ... [et al]. Efficacy of gelatin gel sheets in sustaining the release of basic fibroblast growth factor for murine skin defects. Journal of Surgical Research 2016, 201: 378-387

\section{ISSUE DATE:}

2016-04

URL:

http://hdl.handle.net/2433/262412

\section{RIGHT:}

(C) 2016. This manuscript version is made available under the CC-BY-NC-ND 4.0 license http://creativecommons.org/licenses/by-nc-nd/4.0/:; This is not the published version. Please cite only the published version. この論文は出版社版でありません。引用の際には 出版社版をご確認ご利用ください。 
Efficacy of Gelatin Gel Sheets in Sustaining the Release of Basic Fibroblast Growth Factor for Murine Skin Defects

Michiharu Sakamoto ${ }^{1}$, Naoki Morimoto ${ }^{2}$, Shuichi Ogino ${ }^{1}$, Chizuru Jinnoํ, Tsuguyoshi Taira ${ }^{3}$ and Shigehiko Suzuki ${ }^{1}$.

1 Department of Plastic and Reconstructive Surgery, Kyoto University Graduate School of Medicine, Kawahara-cho 54, Syogoin Sakyo-ku, Kyoto, Japan

2 Department of Plastic and Reconstructive Surgery, Kansai Medical University, Shinmachi 2-3-1, Hirakata-city, Osaka, Japan

3 Gunze Limited Medical Division, Natsumekaichi 46, Aono-cho, Ayabe-city, Kyoto, Japan

E-mail addresses:

Michiharu Sakamoto: dojis@kuhp.kyoto-u.ac.jp 
Shuichi Ogino: m00w0183@kuhp.kyoto-u.ac.jp

Chizuru Jinno: chiitan7@kuhp.kyoto-u.ac.jp

Tsuguyosi Taira: tsuguyoshi.taira@gunze.co.jp

Shigehiko Suzuki: ssuzuk@kuhp.kyoto-u.ac.jp

*Corresponding author:

Naoki Morimoto

E-mail: morimoton@hirakata.kmu.ac.jp

Phone number: +81 757513613

Postal address: Department of Plastic and Reconstructive Surgery, Kansai

Medical University, Shinmachi 2-3-1, Hirakata-city, Osaka, Japan, \#573-1191

Author contributions.

Study conception and design: MS, NM, SO, CJ, SS

Acquisition of data: MS, SO, CJ, TT

Analysis and interpretation of data: MS, NM, TT

Drafting of manuscript: MS, TT 
Critical revision: MS, NM, SS 


\section{Abstract}

\section{Background}

Gelatin has been used as a material sustaining the release of basic fibroblast growth factor (bFGF), which promotes fibroblast proliferation and capillary formation and accelerates wound healing. In the application of these materials, bFGF is impregnated immediately prior to application, and it is difficult to conform the shape to the wound. In this study, we prepared a pliable and plastic gelatin gel sheet (GGS) that sustains bFGF and conforms to the shape of the wound as a result of cross-linking just prior to application. In addition, we examined the sustained release profile of bFGF from GGS and its effect on wound healing in murine skin defects.

Materials and Methods

A $13-w t \%$ gelatin solution was mixed with bFGF before cross-linking with $1 \%$ glutaraldehyde (GA) solution. GGSs impregnated with $7 \mu \mathrm{g} / \mathrm{cm}^{2}$ of $\mathrm{bFGF}$ were incubated in PBS and collagenase solution, and GGS degradation and bFGF release were evaluated. In the murine experiments, GGSs treated without bFGF and GGSs impregnated with $1,3.5,7$ or $14 \mu \mathrm{g} / \mathrm{cm}^{2}$ of $\mathrm{bFGF}$ 
were applied to full-thickness skin defects created on the backs of C57BL/6JJcl mice, and the wound closure, epithelial length and extent of granulation tissue and capillary formation were compared.

Results

Basic FGF was released according to the degradation of GGS in PBS, and the remaining bFGF was released in collagenase solution. In the animal studies, epithelialization was accelerated in the GGSs treated with 1 and $3.5 \mathrm{\mu g} / \mathrm{cm}^{2}$ of bFGF, and granulation tissue formation and angiogenesis were promoted based on the amount of bFGF impregnated into the GGS.

Discussion/Conclusions

GGS impregnated with bFGF is capable of sustaining the release of bFGF, with consequent accelerated epithelialization, granulation tissue formation and angiogenesis in vivo. GGS is a novel and promising wound dressing that sustains bFGF and can be adapted to the shape of various wounds in the treatment of both acute and chronic wounds.

Keywords:

Gelatin gel; basic fibroblast growth factor; sustained release; wound healing; 
murine model; cutometer

\section{Introduction}

Although wound treatment has made progress in recent years, chronic skin ulcers, such as diabetic foot ulcers, venous leg ulcers, ischemic ulcers and decubitus, are still difficult to treat and are costly problems in healthcare (Table 1) [1,2]. In the United States alone, an excess of USD 25 billion is spent annually on the treatment of chronic skin ulcers [3]. At present, several growth factors are clinically available for the treatment of chronic skin ulcers [4-6].

Basic fibroblast growth factor (bFGF), first identified in 1974 by Gospodarowicz, promotes fibroblast proliferation and capillary formation and accelerates wound healing (Fig. 1) [7,8]. In Japan, human recombinant bFGF (FIBRAST SPRAY ${ }^{\circledR}$; Kaken Pharmaceutical, Tokyo, Japan) has been used clinically for the treatment of chronic skin ulcers since 2001, and its clinical effectiveness has been demonstrated [6]. However, this therapy must 
be applied daily due to the short half-life and inactivation of bFGF in vivo, which is a burden for both the medical staff and patient.

In order to overcome this issue, various sustained-release systems for delivering bFGF have been developed [11-14]. Among them, gelatin is one of the most common materials used for the sustained-release of various growth factors, including bFGF [15-17]. We previously developed a novel scaffold, the collagen/gelatin sponge (CGS), which is capable of providing the sustained release of bFGF, platelet-derived growth factor-BB (PDGF-BB) and TGF- $\beta$ and reported the safety and efficacy of CGSs impregnated with bFGF for the treatment of chronic skin ulcers [18-25].

With previous methods, the gelatin carriers are prepared in advance and growth factors, including bFGF, are impregnated just prior to application in vivo or clinically. Therefore, it is difficult to conform the shape of the material to the applied wound. Recently, a novel technique for preparing gelatin gel was reported [26]. In this method, growth factors are incorporated into the gelatin solution, after which gelatin gel containing growth factors is cross-linked with glutaraldehyde. The gelatin gel made using this technique may be an ideal wound dressing, as the gelatin solution is pliable and plastic 
enough to conform to any shape of wound and/or other sites, including tissue defects, prior to cross-linking.

In this study, we examined the sustained release profile of bFGF in our gelatin gel sheet (GGS) using the above method. We then evaluated the effects of the GGSs incorporated with bFGF in treating murine skin defects and explored the appropriate concentrations of bFGF required for wound healing.

\section{Materials and methods}

\section{Ethics statement}

The animals were maintained at the Institute of Laboratory Animals, Graduate School of Medicine, Kyoto University. The number of animals used in this study was kept to a minimum, and all possible efforts were made to reduce their suffering in compliance with the protocols established by the Animal Research Committee of Kyoto University. The animals were anesthetised with isoflurane when they underwent painful procedures. They were sacrificed at the end of the experiment via the inhalation of carbon dioxide gas. Our experimental protocol was approved by the Animal 
Research Committee.(Permit Number: Med Kyo 14569)

\section{Preparation of gelatin gels}

We used gelatin isolated from the pig dermis with an isoelectric point (IEP) of 5.0 and molecular weight of 99,000 (Nippi, Inc., Tokyo, Japan). Gelatin solutions at concentrations of $6.5,13$ and $26 \mathrm{wt} \%$ were prepared by dissolving the gelatin in phosphate-buffered saline (PBS; Life Technologies Japan, Tokyo, Japan) kept at $50^{\circ} \mathrm{C}$. The mixture of gelatin solution (300 $\mu$;

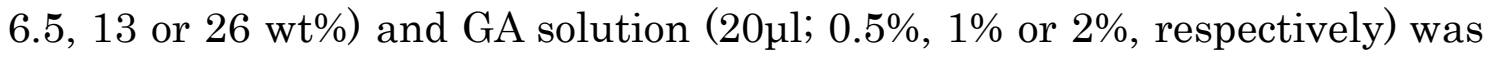
poured, at a temperature of $50^{\circ} \mathrm{C}$, into a cast measuring $12 \mathrm{~mm}$ in diameter (Yahata Neji Co., Ltd., Aichi, Japan) and stirred immediately using a pipet tip, after which gelation formation occurred, usually within 20 seconds after mixing to form a sheet-shaped gelatin gel $12 \mathrm{~mm}$ in diameter and approximately $3 \mathrm{~mm}$ in thickness, called a gelatin gel sheet (GGS) in this study (Fig. 2)

The GGSs were evaluated in an elasticity test, bFGF release study and in vivo study; however, they were too thin to measure the breaking strength. Therefore, column-shaped gelatin gels $5 \mathrm{~mm}$ in diameter and $12 \mathrm{~mm}$ in 
height were prepared for the compression test.

GGSs of 13 wt $\%$ in gelatin concentration, were impregnated with $1,3.5,7$ and $14 \mathrm{\mu g} / \mathrm{cm}^{2}$ of bFGF (FIBRAST SPRAY ${ }^{\circledR}$ Kaken Pharmaceutical, Tokyo, Japan). The bFGF solution was prepared by dissolving bFGF in normal saline solution at a concentration of $125 \mu \mathrm{g} / \mathrm{ml}$. A total of $300 \mu \mathrm{l}$ of $13-\mathrm{wt} \%$ gelatin solution impregnated with $1.1,4.0,7.9$ or $15.8 \mu \mathrm{g}$ of bFGF was prepared by mixing $26^{-}{ }^{-w t} \%$ gelatin solution, $125-\mu \mathrm{g} / \mathrm{ml} \mathrm{bFGF}$ solution and PBS. This mixture was then cross-linked with $20 \mu \mathrm{l}$ of $1 \%$ GA in a 12 -mm diameter cast to prepare GGSs with $1,3.5,7$ or $14 \mu \mathrm{g} / \mathrm{cm}^{2}$ of $\mathrm{bFGF}$, respectively.

\section{Compression test of the gelatin gels}

The compression test was performed using a universal testing machine (EZ-Graph, Shimadzu Corporation, Japan) to investigate the breaking strength of each gelatin gel. Columnar gelatin gels with a gelatin concentration of $6.5,13$ and $26 \mathrm{wt} \%$, measuring $5 \mathrm{~mm}$ in diameter and $12 \mathrm{~mm}$ in height, were prepared $(\mathrm{n}=4)$. Precisely, $6 \mathrm{ml}$ of gelatin solution $(6.5,13$ or $26 \mathrm{wt} \%)$ and $0.4 \mathrm{ml}$ of GA solution $(0.5 \%, 1 \%$ or $2 \%$, 
respectively) were mixed and poured using an applicator, into four casts measuring $5 \mathrm{~mm}$ in diameter and $12 \mathrm{~mm}$ in depth. The gelatin gels were incubated at $37^{\circ} \mathrm{C}$ for one hour and subsequently compressed with a probe measuring $4 \mathrm{~mm}$ in diameter, and the breaking strength, the compression strength at which each gel was collapsed by the probe, was measured four times. The average strength was used for the analysis.

\section{Elasticity test of the GGSs}

A skin elasticity meter, Cutometer ${ }^{\circledR}$ MPA 580 (Courage and Khazaka Electronic GmbH, Cologne, Germany) was used to evaluate the elasticity of the GGSs. The Cutometer ${ }^{\circledR}$ is capable of measuring the degree of vertical deformation of the material by suctioning into a round probe $2 \mathrm{~mm}$ in diameter [27]. The device applies 500 mbar at maximum; however, suctioning with a vacuum load over 300 mbar resulted in the collapse of the GGS surface. Therefore, a vacuum load of 100 mbar was placed over the gelatin gel surface for five seconds followed by the application of a normal pressure for three seconds. Various parameters intended to measure different aspects of deformation of the skin are derived from the 
deformation-time curve of the Cutometer ${ }^{\circledR}$ [28]. In this study, Uf (depicted as R0), the maximal extension of deformation at the end of the vacuum period, was used to evaluate the elasticity of the GGSs.

GGSs with a gelatin concentration of $6.5,13$ and 26 wt\% (n=4) were prepared, and the elasticity of each GGS was measured. Each measurement was repeated three times at different points in the materials, and the mean values were used.

\section{Basic FGF release from the GGSs in vitro}

We enzymatically degraded GGSs using collagenase and measured gelatin degradation and the amount of released bFGF according to a previously reported method [21, 23]. A total of 39 GGSs composed of $13^{-}$wt $\%$ gelatin impregnated with $7 \mu \mathrm{g} / \mathrm{cm}^{2}$ of bFGF were used. The GGSs $(n=3)$ were stored at $-80^{\circ} \mathrm{C}$ in order to measure their initial dry weight. Each GGS ( $\left.n=36\right)$ was placed in a polypropylene tube (Corning centrifuge tube, Corning Incorporated Life Sciences, MA, USA), after which $2.5 \mathrm{ml}$ of PBS was added to each tube and the tubes were incubated at $37^{\circ} \mathrm{C}$. A total of $200 \mu \mathrm{l}$ of media and the remaining GGS were collected at 2, 4, 6, 8, 12 and 24 hours after 
incubation ( $\mathrm{n}=3$ at each point). The media were frozen and preserved at $-30^{\circ} \mathrm{C}$, and the GGSs were frozen and kept at $-80^{\circ} \mathrm{C}$ until the measurements. After 24 hours of incubation, the PBS was discarded from the remaining tubes $(\mathrm{n}=18)$, and $2.5 \mathrm{ml}$ of PBS containing $2 \mathrm{U} / \mathrm{ml}$ of collagenase (Sigma Chemical, St Louis, MO) was added to each tube. We determined the concentration of collagenase that was required to degrade a whole GGS in 24 $\mathrm{h}$ of incubation.

The tubes were incubated at $37^{\circ} \mathrm{C}$, and $200 \mu \mathrm{l}$ of the media and the GGSs were collected at $2,4,6,8,12$ and 24 hours after replacement $(n=3$ at each point). The media were frozen and preserved at $-30^{\circ} \mathrm{C}$, and the GGSs were frozen and kept at $-80^{\circ} \mathrm{C}$ until the measurements.

The frozen GGSs were freeze dried with a freeze dryer VD-250R (TAITEC, Saitama, Japan) overnight, and the dry weight was measured. The bFGF concentration in the media was measured using an enzyme-linked immunosorbent assay (ELISA) (Quantikine ${ }^{\circledR}$ ELISA kit, R\&D Systems, Minneapolis, MN), according to the manufacturer's instructions. Briefly, the samples were added to 96 -well plates coated with anti-bFGF antibodies. After incubating the plates and removing the unbound substances, an 
enzyme-coupled secondary antibody was added to the wells in the plates.

Following the color reactions, we used a spectrophotometer (VersaMax;

Molecular Devices, Tokyo, Japan) to measure the optical density of the product at a test wavelength of $450 \mathrm{~nm}$ and reference wavelength of $540 \mathrm{~nm}$.

The amount of bFGF released at each sampling time was then calculated.

The weight of each degraded GGS is shown as the percentage relative to the initial GGS weight.

\section{Effectiveness of the GGSs impregnated with bFGF in promoting wound healing}

\subsection{Application of GGSs}

GGS without bFGF and four kinds of GGSs impregnated with 1, 3.5, 7 or

$14 \mathrm{\mu g} / \mathrm{cm}^{2}$ of $\mathrm{bFGF}$ were used ( $\mathrm{n}=15$ in each group). Eight-week-old C57BL/6JJcl male mice (CLEA Japan, Inc., Tokyo, Japan) were assigned to five groups, including a control group and four GGS with bFGF treatment groups $(\mathrm{n}=15)$. We used male mice to avoid the influence of menstruation. A GGS treated without bFGF was used in the control group, and GGSs treated with $1,3.5,7$ and $14 \mu \mathrm{g} / \mathrm{cm}^{2}$ of bFGF were used in the bFGF $1,3.5,7$ and 14 
groups, respectively.

Following shaving and depilation, a full-thickness skin defect measuring $8 \mathrm{~mm}$ in diameter was created on the dorsum of each mouse under general anesthesia with the inhalation of $1.5 \%$ isoflurane (Wako Pure Chemical Industries Ltd, Osaka, Japan) as the maintenance dose. Each wound was covered with a GGS treated with or without bFGF, and a polyethylene film (Tegaderm ${ }^{\circledR}, 3 \mathrm{M}$ Health Care, St. Paul, MN, USA) was applied on the GGS to prevent drying, after which the site was fixed with a surgical bandage (Silkytex®, Alcare Co., Ltd., Tokyo, Japan).

\subsection{Assessment of the wound area and epithelialization}

The mice were sacrificed at one, two and three weeks after the operation $(n=5$ in each group) via the inhalation of carbon dioxide gas. Gross photographs were obtained with a digital camera, and the tissue specimens were harvested. The wound area was measured using the Image-J software program, ver. 1.45 (NIH, Maryland, USA) and is shown as the percentage relative to the original wound area. The specimens were fixed in $10 \%$ neutral-buffered formalin solution, paraffin embedded and sectioned at the 
central area of each wound, and hematoxylin-eosin (HE) staining was subsequently performed. The length of the neoepithelium was determined in accordance with the methods of previous reports $[19,29,30]$ : the length from the last hair follicle of the marginal skin to the end of the epithelium was measured on the HE-stained sections using an optical microscope (KEYENCE BZ-9000 and BZ-II Analyzer ver. 1.42, KEYENCE Japan, Osaka, Japan).

\subsection{Assessment of granulation tissue}

Azan staining of the specimens was performed at one week after the operation. The area and thickness of the newly formed granulation tissue on the sections prepared from the center of the wounds was measured. The granulation thickness was measured at three points (left edge, center and right edge of the newly formed granulation tissue in the wound) in each section and the mean thickness was used. The granulation area was measured according to the previously reported method [20]. Briefly, the area between both levels of marginal skin on the underlying muscle layer was measured on Azan-stained sections using an optical microscope. $(\mathrm{n}=5$ in each 
group)

\subsection{Immunohistological staining and evaluation of newly formed capillaries}

Immunohistological staining with von Willebrand factor was performed to detect newly formed capillaries. Then, 6- $\mu \mathrm{m}$ sections were dewaxed and rehydrated and subsequently incubated in antigen retrieval solution (Dako Japan, Tokyo, Japan) for 30 minutes at $80^{\circ} \mathrm{C}$. Anti-von Willebrand Factor rabbit polyclonal antibodies (Code No. A0082; Dako Japan) were used as the primary antibody (1:300 dilution), after which Histofine ${ }^{\circledR}$ Simple Stain ${ }^{\mathrm{TM}}$ Mouse MAX-PO(R) (Nichirei Biosciences Inc., Tokyo, Japan) was applied. The sections were exposed to DAB (3-3'-diaminobenzidine-4HCl) (Nichirei Biosciences Inc.) for 20 seconds at room temperature, and counterstaining was performed with hematoxylin. Digital light micrographs of the sections were taken at 100x magnification. In each section, two squares of $400 \mu \mathrm{m}$ in width and height were chosen from the central region beyond the muscle layer. The number and cross-sectioned area of newly formed capillaries in the two squares in each section were measured using the BZ-II Analyzer imaging software program (version 1.42; KEYENCE Co., Osaka, Japan), and 
the mean values were calculated.

\section{Statistical analysis}

Statistical significance was identified based on the Tukey-Kramer test.

All data are expressed as the mean \pm standard deviation. A P value of $<0.05$

was accepted as being statistically significant.

\section{Results}

\section{Breaking strength of the gelatin gels}

The breaking strength of the gelatin gels with $6.5,13$ and $26 \mathrm{wt} \%$ gelatin was $1.92 \pm 0.27,10.23 \pm 0.7$ and $30.02 \pm 2.82(\mathrm{~N})$, respectively. The breaking strength of the $26-\mathrm{wt} \%$ gelatin gel was significantly higher than that of the 6.5- and $13^{-}$wt\% gelatin gels $(\mathrm{P}<0.01)$, whereas the breaking strength of the $13^{-}$wt\% gel was significantly higher than that of the $6.5-\mathrm{wt} \%$ gel $(\mathrm{P}<0.05)$ $(n=4)$. Therefore, a higher concentration of gelatin was associated with a higher breaking strength in the concentration range employed in this study.

\section{Elasticity of the GGSs}


The Uf (R0) values of the 6.5-, $13^{-}$and $26^{-}$wt\% GGS were $0.28 \pm 0.12$, $0.07 \pm 0.03$ and $0.04 \pm 0.01(\mathrm{~mm})$, respectively. The Uf value of the $6.5-\mathrm{wt} \%$ GGS was significantly greater than that of the $13^{-}$and $26^{-}$wt $\%$ gels $(p<0.01)$ $(n=4)$.

A softer material is desirable as a wound dressing because it flexibly fits along the wound surface; however, the 6.5 -wt\% GGS was too flexible to maintain its shape on the wounds. Therefore, we used the $13-\mathrm{wt} \%$ GGS in the following experiments.

\section{Rate of degradation of the gelatin gels and bFGF release}

The time course of degradation of GGS and release of bFGF are shown in Figure 3. The decreased dry weight of the GGSs incubated for 24 hours was $39.4 \pm 6.8 \%$. After incubation in collagenase solution, the GGSs were promptly degraded, with complete degradation after 24 hours of incubation in collagenase solution. The amount of bFGF released at two hours after incubation in PBS was $0.61 \pm 0.15 \mu \mathrm{g}$. The amount of released bFGF tended to decrease gradually, being $0.28 \pm 0.02 \mu \mathrm{g}$ at 24 hours. Basic FGF was 
promptly released in the collagenase solution after the replacement of PBS with collagenase.

\section{Wound area}

The gross appearance of the wounds at one, two and three weeks after the operation are shown in Figure 4A. The wounds were not yet epithelialized at two weeks in the control group and the bFGF 7 and 14 groups; however, all wounds were epithelialized at three weeks. At two weeks after the operation, the GGSs that were applied to the wounds were degraded and only small pieces remained. At three weeks after the operation, the GGSs were completely dehydrated.

There were no significant differences in the wound area at one week. At two weeks after the operation, the wound area in the bFGF 7 group was significantly larger than that in the bFGF 1 group $(\mathrm{P}<0.05)$, and the wound area in the bFGF 14 group was significantly larger than that in the control group $(\mathrm{p}<0.05)$ as well as the bFGF $1(\mathrm{p}<0.01)$ and $3.5(\mathrm{p}<0.05)$ groups. $(\mathrm{n}=5)$ (Fig. 4B) 


\section{Histological assessment of the length of the neoepithelium}

Figure 5A shows HE staining micrographs of the wounds in the control group and the bFGF 1, 3.5, 7 and 14 groups two weeks after the operation. The neoepithelium length was significantly longer in the bFGF 1 and 3.5 groups at two weeks than in the control group $(\mathrm{p}<0.01)$ or bFGF 14 group $(\mathrm{p}<0.05)$. (Fig. 5B)

All of the wounds had been already epithelialized and severe contracture was observed at three weeks after the operation. The variation of scar width was very large and showed no clear trend and the epithelium length did not differ to a statistically significant extent among the five groups.

\section{Assessment of granulation tissue}

Azan staining micrographs of the wounds in the control group and the bFGF 1, 3.5, 7 and 14 groups at one week after the operation are shown in Figure 6A. The cross-sectional area of newly formed granulation increased according to the amount of bFGF impregnated with the GGSs. The cross-sectional area of granulation tissue in the bFGF 14 group was 
significantly larger than that noted in the control group or bFGF 1, 3.5 and 7 groups $(p<0.01)$, while that in the bFGF 7 group was significantly larger than that seen in the control group or bFGF 1 group $(\mathrm{p}<0.01)$ and that in the bFGF 3.5 group was significantly larger than that identified in the control group $(\mathrm{p}<0.01)$ or bFGF 1 group $(\mathrm{p}<0.05)$. (Fig. 6B) As in the cross-sectional area of granulation tissue, the granulation thickness in each group was increased according to the amount of bFGF in the impregnated GGSs (Fig. $6 \mathrm{C})$.

\section{Evaluation of newly formed capillaries in the wounds}

Light micrographs of the wounds in the sections immunohistologically stained with von Willebrand Factor two weeks after the operation are shown in Figure 7A. The number of capillaries in the bFGF 3.5 and 7 groups was significantly larger than that observed in the control group $(p<0.05)$, while that in the bFGF 14 group was significantly larger than that noted in the control group or bFGF 1 group $(\mathrm{p}<0.01)$.(Fig. 7B) The gross area of capillaries in the bFGF 7 and 14 groups was significantly larger than that seen in the control group or bFGF 1 group (Fig. 7C). 


\section{Discussion}

In this study, we examined the sustained release of bFGF from GGS and its effect on murine skin defects. When preparing the GGSs, we used GA for cross-linking just after impregnation of bFGF and applied the gels in vivo. GA is widely used in the medical field, and its toxicity has been sufficiently explored. However, there remains the possibility that, when preparing GGS, residual free GA may affect the wound healing process and/or denaturalize bFGF during the cross-linking process.

Regarding the residual free GA, Suzuki et al. investigated the cytotoxicity of the GA released from the gelatin gel cross-linked with GA. They prepared an extract from the gelatin gel by immersing the gel in Dulbecco's Modified Eagle Medium and reported that the extract from gelatin gel had lower cytotoxicity than pristine GA solution, as almost all of the GA was bound to gelatin molecules [31]. In the current study, neither inflammation on the $\mathrm{HE}$ sections nor retardation of wound healing were observed compared with the findings of our previous study, and the effect of residual free GA was not confirmed. 
Regarding the denaturation of bFGF induced by GA, we confirmed the sustained release of bFGF from the 13-wt $\%$ GGS. Approximately $40 \%$ of GGS was degraded in PBS without collagenase for 24 hours, and the rest was degraded completely in collagenase solution over the following 24 hours. Basic FGF was also released according to the degradation of GGS in PBS, and the remaining bFGF was released in collagenase solution. These observations show that bFGF was maintained after the cross-linking. A total of $0.61 \mathrm{\mu g}$ of bFGF was released at the $2 \mathrm{~h}$ timepoint and the amount of released bFGF showed a gradual decrease thereafter until the $24 \mathrm{~h}$ timepoint. We confirmed that the concentration of bFGF in the pristine bFGF solution would decrease when it was incubated in polypropylene tubes at $37^{\circ} \mathrm{C}$. (Supp 1.) As milk casein moderated the bFGF decrease, it was estimated that absorption of bFGF into the wall of the polypropylene tube was one reason for the decrease in the amount of bFGF. Basic FGF proteins are also known to be sensitive to thermal denaturation [32]. In any case, it is certain that bFGF was released by the enzymatic degradation of the GGSs as the amount of released bFGF was substantially increased after incubation 
with collagenase. It was also apparent, from the in vivo study that the bFGF released from the GGSs actually had biological activity.

The results of the release profile study suggest that the release of bFGF from GGS involves two different systems, similar to the results of previous reports. Basic FGF is released mainly due to the effects of simple diffusion at first, as shown in PBS in this study. In the next step, bFGF ionically adsorbed to gelatin molecules is released via the enzymatic degradation of gelatin, as shown in the collagenase solution. The gelatin gel with an IEP of 5.0 used in this study is able to form an ion complex with bFGF, with an IEP of 9.6. This release profile is unique to GGS and suggests that the released growth factors may be altered by using gelatin with a suitable IEP.

The mice experiments with the GGSs showed that epithelialization was accelerated at 1 and $3.5 \mu \mathrm{g} / \mathrm{cm}^{2}$ of $\mathrm{bFGF}$, whereas the formation of granulation tissue and capillary formation were promoted according to the amount of bFGF impregnated into the GGSs treated with bFGF at a concentration up to $14 \mathrm{\mu g} / \mathrm{cm}^{2}$. This observation is consistent with our previous findings for a murine wound healing model using a collagen/gelatin sponge (CGS) that acts as a scaffold sustaining the release of bFGF [19,21]. 
In those studies, the application of CGSs impregnated with bFGF of $7 \mu \mathrm{g} / \mathrm{cm}^{2}$ accelerated the epithelialization, although such epithelialization was delayed with the CGSs at an impregnation dose of more than $14 \mathrm{\mu g} / \mathrm{cm}^{2}$. It has been reported that the bioactivity of bFGF exhibits a bell-shaped effect. For example, Okumura et al. reported the bell-shaped effect of bFGF on epithelialization and acceleration of wound closure using a full-thickness skin defect model in genetically diabetic mice [33], and Tanaka et al. reported that the level of bFGF that exceeds the optimal range was associated with the decreased proliferation of keratinocytes [34]. The current results showed that the optimum concentration of bFGF for epithelialization was lower than that for granulation tissue formation and angiogenesis, consistent with our previous results for CGS. We suppose that the use of GGSs with a high dose of bFGF in this study excessively promoted the regeneration of granulation and angiogenesis, resulting in the disturbance of epithelialization and wound area reduction.

When applying the GGS reported in this study clinically, it should be kept in mind that the bFGF dose must be changed based on the purpose of treatment. GGSs with a low amount of bFGF are suitable for accelerating 
epithelialization, while GGSs with a high amount of bFGF are appropriate for promoting granulation tissue formation and angiogenesis in full-thickness skin defects or intractable skin ulcers. This result is also compatible with our previous findings for CGSs [19-21].

Although this study used acute full thickness skin defects, GGSs impregnated with bFGF are also expected to effectively heal chronic wounds, since bFGF released from CGSs was shown to effectively heal DM mouse model wounds in our previous reports [19, 21]. The GGS presented in this study has the ideal level of plasticity, so that its shape can be arranged easily and applied to various kinds of wounds, regardless of their form. In addition, other than application to skin wounds, this technique may be used to accelerate tissue repair at sites of vascular anastomosis or intestinal anastomosis by applying a mixed solution of gelatin containing bFGF and GA. Depending on the purpose, other growth factors than bFGF may also be impregnated into the GGS.

\section{Conclusion}

This study showed that GGS prepared by mixing bFGF with gelatin 
solution just before cross-linking with GA is capable of sustaining the release

of bFGF. In particular, GGSs impregnated with bFGF accelerated epithelialization, granulation tissue formation and angiogenesis in vivo. Our GGS material is a novel and promising wound dressing that sustains bFGF and may be adapted to the shape of various wounds in the treatment of both acute and chronic wounds.

\section{Disclosure}

The authors have no competing interests to declare.. 


\section{Figure captions}

Fig. 1. The acceleration of wound healing by bFGF

Fig. 2. Gelatin gel sheet with a gelatin concentration of $13 \mathrm{wt} \%$.

Fig. 3. Rate of degradation of the gelatin gels and bFGF release. OTime course of the mean \pm standard deviation percentage of degraded gelatin.

The mean \pm standard deviation of bFGF released from the GGSs treated with bFGF. The arrow indicates the time at which the addition of PBS solution was stopped and the addition of collagenase was initiated. Both the rate of degradation of gelatin and amount of released bFGF sharply increased following the addition of collagenase. ( $\mathrm{n}=3$ at each timepoint)

Fig. 4. A) Gross appearance of the wounds. The gross appearance of the wounds in the control group and bFGF 1, 3.5, 7 and 14 groups immediately after the operation $(0 \mathrm{w})$ and one, two and three weeks after the operation is shown. The yellow circles indicate the initial wound size: $8 \mathrm{~mm}$ in diameter. The wounds in the bFGF 1 and 3.5 groups two weeks after the operation and those in all groups three weeks after the operation were completely 
epithelialized. B) Wound area. The mean remaining wound areas \pm standard deviation in the control group and bFGF 1, 3.5, 7, 14 groups are shown. The remaining wound area in the bFGF 7 group was significantly larger than that observed in the bFGF 1 group, and the wound area in the bFGF 14 group was significantly larger than that observed in the control, bFGF 1 and 3.5 groups two weeks after the operation $(n=5) .{ }^{*} p<0.05,{ }^{* *} p<0.01$.

Fig. 5. A) Hematoxylin and eosin staining micrographs of the wounds. Micrographs of the sections in the control group and the bFGF 1, 3.5, 7 and 14 groups two weeks after the operation are shown. The arrows indicate the neoepithelium. Scale bar: $300 \mu \mathrm{m}$. B) Mean neoepithelium length. The mean neoepithelium length $(\mathrm{mm}) \pm$ standard deviation in the control group and bFGF 1, 3.5, 7 and 14 groups one and two weeks after the operation is shown. No significant differences were found in the neoepithelium length at one week after the operation. The neoepithelium length was significantly longer in the bFGF 1 and 3.5 groups at two weeks than in the control group $(p<0.01)$ or bFGF 14 group $(\mathrm{p}<0.05) .(\mathrm{n}=5) * \mathrm{p}<0.05,{ }^{* *} \mathrm{p}<0.01$. 
Fig. 6. A) Azan staining micrographs of the wounds. Micrographs in the control group and the bFGF $1,3.5,7$ and 14 groups one week after the operation are shown. The dotted lines indicate the newly formed granulation tissue surrounded by the marginal skin dermis and underlying muscle layer.

Scale bar: $300 \mu \mathrm{m}$. B) Cross-sectional area of granulation tissue. The mean cross-sectional areas \pm standard deviation of granulation tissue in the control group and the bFGF 1, 3.5, 7 and 14 groups one week after the operation are shown. The cross-sectional area of granulation tissue in the bFGF 14 group was significantly larger than that observed in the control group or bFGF 1 , 3.5 and 7 groups $(p<0.01)$, while that in the bFGF 7 group was significantly larger than that seen in the control group or bFGF 1 group $(p<0.01)$ and that in the bFGF 3.5 group was significantly larger than that noted in the control group $(p<0.01)$ or bFGF 1 group $(p<0.05)(n=5) .{ }^{*} p<0.05,{ }^{* *} p<0.01$. C) Granulation thickness. The mean \pm standard deviation of the granulation thicknesses in the control group and the bFGF 1, 3.5, 7 and 14 groups at one week after the operation are shown $(n=5)$. The granulation thickness in each group was increased according to the amount of bFGF with which the GGS had been impregnated. ${ }^{*} \mathrm{p}<0.05,{ }^{* *} \mathrm{p}<0.01$ 
Fig. 7. A) Immunohistological staining for von Willebrand Factor. Immunohistological staining of the newly formed capillaries with von Willebrand Factor in the wounds in the control group and the bFGF 1, 3.5, 7 and 14 groups two weeks after the operation is shown. The black arrowheads indicate newly formed capillaries. Scale bar: $100 \mu \mathrm{m}$. B) Number of capillaries. The mean number \pm standard deviation of capillaries in the control group and the bFGF 1, 3.5, 7 and 14 groups two weeks after the operation is shown. The number of capillaries in the bFGF 3.5 and 7 groups was significantly larger than that determined in the control group $(p<0.05)$, while that in the bFGF 14 group was significantly larger than that seen in the control group or bFGF 1 group $(\mathrm{p}<0.01) .{ }^{*} \mathrm{p}<0.05,{ }^{* *} \mathrm{p}<0.01$. C) Area of capillaries. The mean gross area \pm standard deviation of capillaries in the control group and the bFGF 1, 3.5, 7 and 14 groups two weeks after the operation is shown. The gross area of capillaries in the bFGF 7 and 14 groups was significantly larger than that observed in the control group or bFGF 1 group. $(\mathrm{n}=5) * * \mathrm{p}<0.01$. 


\section{References}

1. Frykberg RG, Banks J. Challenges in the Treatment of Chronic Wounds. Adv Wound Care (New Rochelle). 2015; 4(9): 560-82.

2. Lal BK. Venous ulcers of the lower extremity: Definition, epidemiology, and economic and social burdens. Semin Vasc Surg. 2015; 28(1): 3-5. doi: 10.1053/j.semvascsurg.2015.05.002. Epub 2015 May 8.

3. Sen CK, Gordillo GM, Roy S, Kirsner R, Lambert L, Hunt TK, et al. Human skin wounds: a major and snowballing threat to public health and the economy. Wound Repair Regen. 2009; 17(6): 763-71.

4. Fang RC, Galiano RD. A review of becaplermin gel in the treatment of diabetic neuropathic foot ulcers. Biologics. 2008; 2(1): 1-12. 
5. Tiaka EK, Papanas N, Manolakis AC, and Georgiadis GS. Epidermal growth factor in the treatment of diabetic foot ulcers: an update. Perspect Vasc Surg Endovasc Ther 2012; 24(1): 37-44.

6. Akita S, Akino K, Tanaka K, Anraku K, Hirano A. A basic fibroblast growth factor improves lower extremity wound healing with a porcine-derived skin substitute. J Trauma. 2008; 64: 809-15.

7. Gospodarowicz D. Localisation of a fibroblast growth factor and its effect alone and with hydrocortisone on 3T3 cell growth. Nature. 1974; 249(453): 123-7.

8. McGee GS, Davidson JM, Buckley A, Sommer A, Woodward SC, Aquino AM, et al. Recombinant basic fibroblast growth factor accelerates wound healing. J Surg Res. 1988; 45(1): 145-53.

9. Ledoux D, Gannoun-Zaki L, Barritault D. Interactions of FGFs with target cells. Prog Growth Factor Res. 1992; 4(2): 107-20. 
10. Yun YR, Won JE, Jeon E, Lee S, Kang W, Jo H, et al. Fibroblast growth factors: biology, function, and application for tissue regeneration. J Tissue Eng. 2010; 2010:218142. doi: 10.4061/2010/218142.

11. Wissink MJ, Beernink R, Pieper JS, Poot AA, Engbers GH, Beugeling T, et al. Binding and release of basic fibroblast growth factor from heparinized collagen matrices. Biomaterials. 2001; 22(16): 2291-9.

12. Tanihara M, Suzuki Y, Yamamoto E, Noguchi A, Mizushima Y. Sustained release of basic fibroblast growth factor and angiogenesis in a novel covalently crosslinked gel of heparin and alginate. J Biomed Mater Res. $2001 ; 56(2): 216-21$.

13. Nakamura S, Kanatani Y, Kishimoto S, Nakamura S, Ohno C, Horio T, et al. Controlled release of FGF-2 using fragmin/protamine microparticles and effect on neovascularization. J Biomed Mater Res A. 2009; 91(3): 814-23. 
14. Tabata Y, Ikada Y. Vascularization effect of basic fibroblast growth factor released from gelatin hydrogels with different biodegradabilities. Biomaterials. 1999; 20(22): 2169-75.

15. Hong L, Tabata Y, Miyamoto S, Yamamoto M, Yamada K, Hashimoto N, et al. Bone regeneration at rabbit skull defects treated with transforming growth factor-beta1 incorporated into hydrogels with different levels of biodegradability. J Neurosurg. 2000; 92(2): 315-25.

16. Asamura S, Mochizuki Y, Yamamoto M, Tabata Y, Isogai N. Bone regeneration using a bone morphogenetic protein-2 saturated slow-release gelatin hydrogel sheet: evaluation in a canine orbital floor fracture model. Ann Plast Surg. 2010; 64(4): 496-502.

17. Matsui M, Tabata Y. Enhanced angiogenesis by multiple release of platelet-rich plasma contents and basic fibroblast growth factor from gelatin hydrogels. Acta Biomater. 2012; 8(5): 1792-801. 
18. Takemoto S, Morimoto N, Kimura Y, Taira T, Kitagawa T, Tomihata K, et al. Preparation of collagen/gelatin sponge scaffold for sustained release of bFGF. Tissue Eng Part A. 2008; 14(10): 1629-38.

19. Kanda N, Morimoto N, Takemoto S, Ayvazyan AA, Kawai K, Sakamoto Y, et al. Efficacy of novel collagen/gelatin scaffold with sustained release of basic fibroblast growth factor for dermis-like tissue regeneration. Ann Plast Surg. 2012; 9(5): 569-74.

20. Ayvazyan A, Morimoto N, Kanda N, Takemoto S, Kawai K, Sakamoto Y, et al. Collagen-gelatin scaffold impregnated with bFGF accelerates palatal wound healing of palatal mucosa in dogs. J Surg Res. 2011; 171(2): e247-57.

21. Kanda N, Morimoto N, Ayvazyan AA, Takemoto S, Kawai K, Nakamura Y, et al. Evaluation of a novel collagen-gelatin scaffold for achieving the sustained release of basic fibroblast growth factor in a diabetic mouse model. J Tissue Eng Regen Med. 2014; 8(1): 29-40. 
22. Morimoto N, Ito T, Takemoto S, Katakami M, Kanda N, Tada H, et al. An exploratory clinical study on the safety and efficacy of an autologous fibroblast-seeded artificial skin cultured with animal product-free medium in patients with diabetic foot ulcers. Int Wound J. 2014; 11(2): $183-9$.

23. Ito R, Morimoto N, Liem PH, Nakamura Y, Kawai K, Taira T, et al. Adipogenesis using human adipose tissue-derived stromal cells combined with a collagen/gelatin sponge sustaining release of basic fibroblast growth factor. J Tissue Eng Regen Med. 2014; 8(12): 1000-8.

24. Ito R, Morimoto N, Pham LH, Taira T, Kawai K, Suzuki S. Efficacy of the controlled release of concentrated platelet lysate from a collagen/gelatin scaffold for dermis-like tissue regeneration. Tissue Eng Part A. 2013; 19(11-12): 1398-405. 
25. Morimoto N, Yoshimura K, Niimi M, Ito T, Aya R, Fujitaka J, et al. Novel collagen/gelatin scaffold with sustained release of basic fibroblast growth factor: clinical trial for chronic skin ulcers. Tissue Eng Part A. 2013; 19(17-18): 1931-40.

26. Suzuki S, Morimoto N, Ikada Y. Gelatin gel as a carrier of platelet-derived growth factors. J Biomater Appl. 2013; 28(4): 595-606.

27. Murray BC, Wickett RR. Correlations between dermal torque meter, cutometer, and dermal phase meter measurements of human skin. Skin Res Technol. 1997; 3: 101-6.

28. Draaijers LJ, Botman YA, Tempelman FR, Kreis RW, Middelkoop E, van Zuijlen PP. Skin elasticity meter or subjective evaluation in scars: a reliability assessment. Burns. 2004; 30(2): 109-14.

29. Liem PH, Morimoto N, Ito R, Kawai K, Suzuki S. Treating a collagen scaffold with a low concentration of nicotine promoted angiogenesis and wound healing. J Surg Res. 2013; 182(2): 353-61. 
30. Tamariz E, Marsch-Moreno M, Castro-Muñozledo F, Tsutsumi V, Kuri-Harcuch W. Frozen cultured sheets of human epidermal keratinocytes enhance healing of full-thickness wounds in mice. Cell Tissue Res. 1999; 296(3): 575-85.

31. Suzuki S, Ikada Y. Sealing effects of cross-linked gelatin. J Biomater Appl. 2013; 27(7): 801-10.

32. Levenstein ME, Ludwig TE, Xu RH, Llanas RA, VanDenHeuvel-Kramer K, Manning D, et al. Basic fibroblast growth factor support of human embryonic stem cell self-renewal. Stem Cells. 2006; 24(3): 568-74.

33. Okumura M, Okuda T, Nakamura T, Yajima M. Acceleration of wound healing in diabetic mice by basic fibroblast growth factor. Biol Pharm Bull. $1996 ; 19(4): 530-5$. 
34. Tanaka E, Ase K, Okuda T, Okumura M, Nogimori K. Mechanism of acceleration of wound healing by basic fibroblast growth factor in genetically diabetic mice. Biol Pharm Bull. 1996; 19(9): 1141-8. 


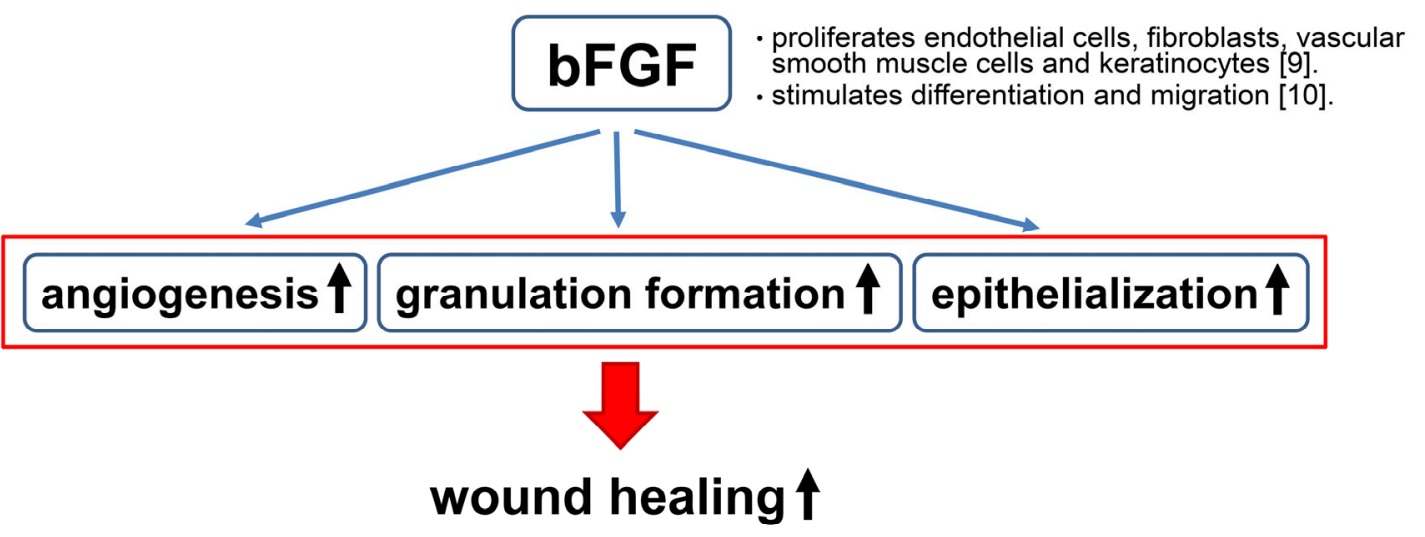

Fig.1

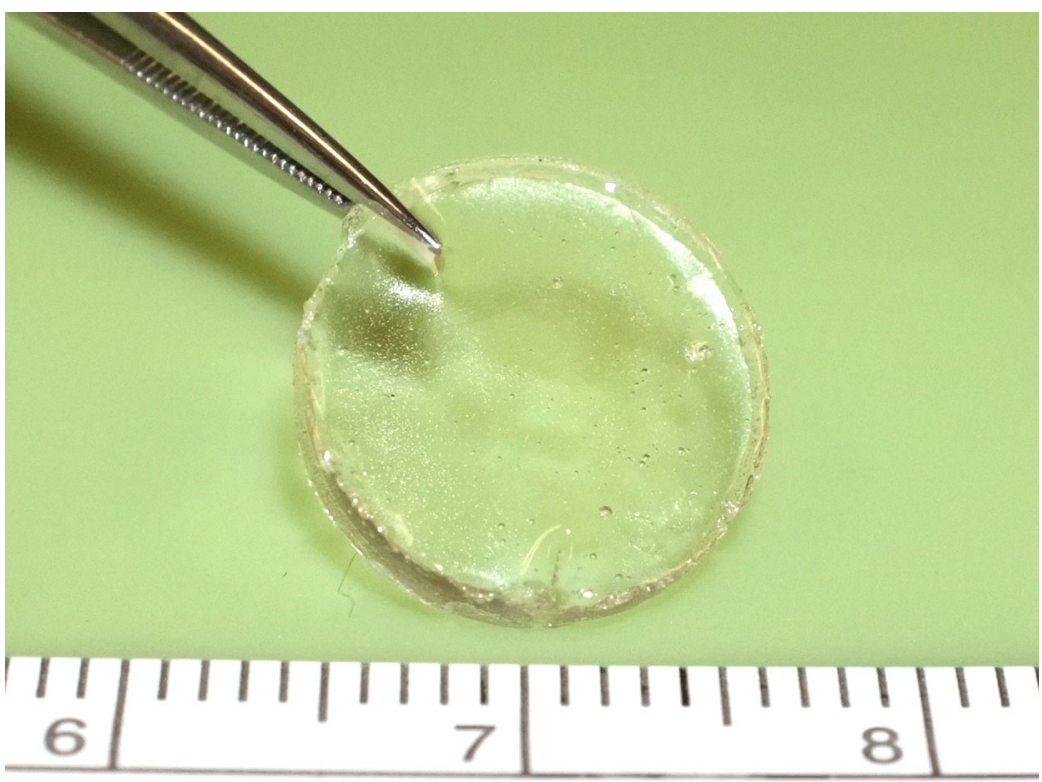

Fig.2 


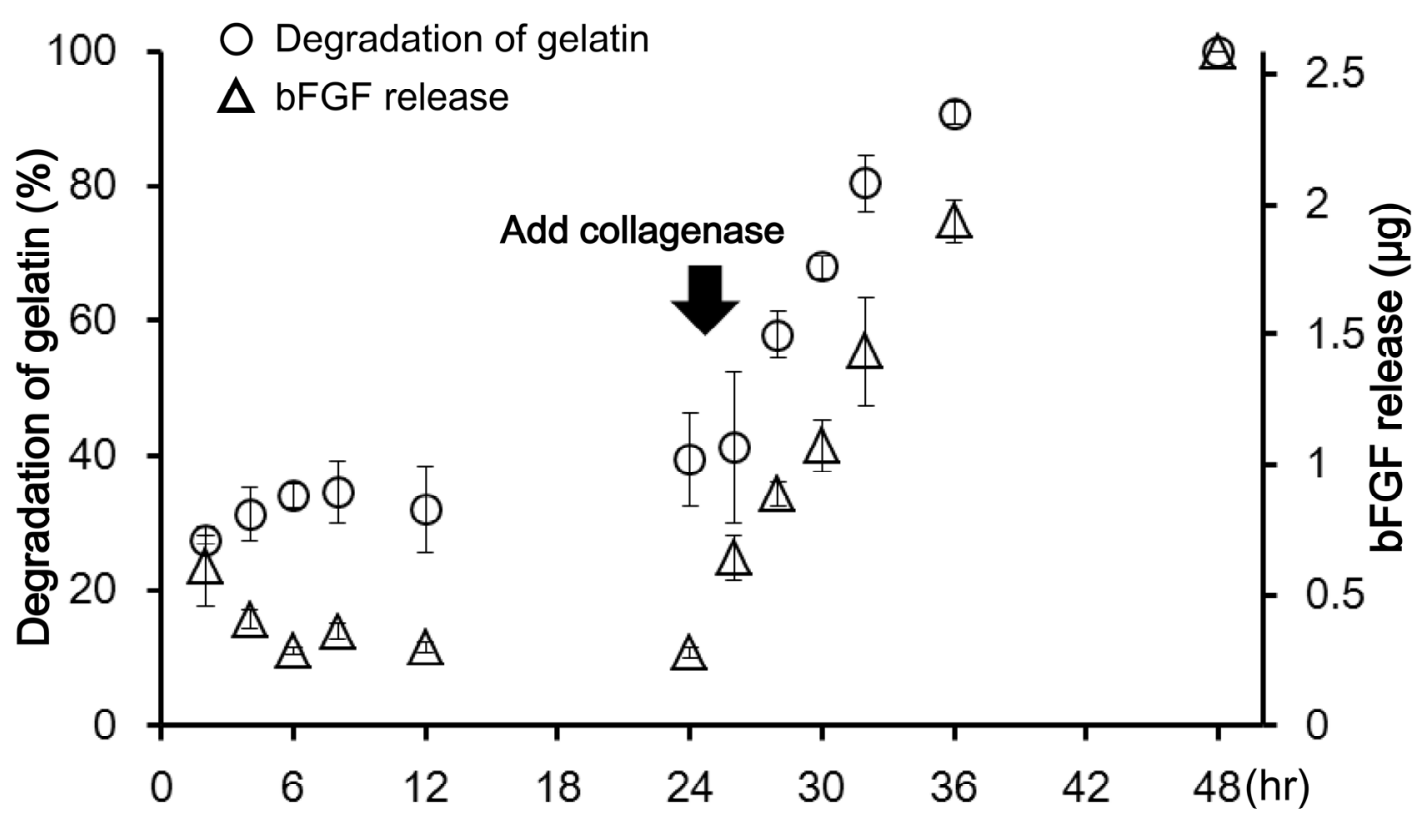

Fig. 3 

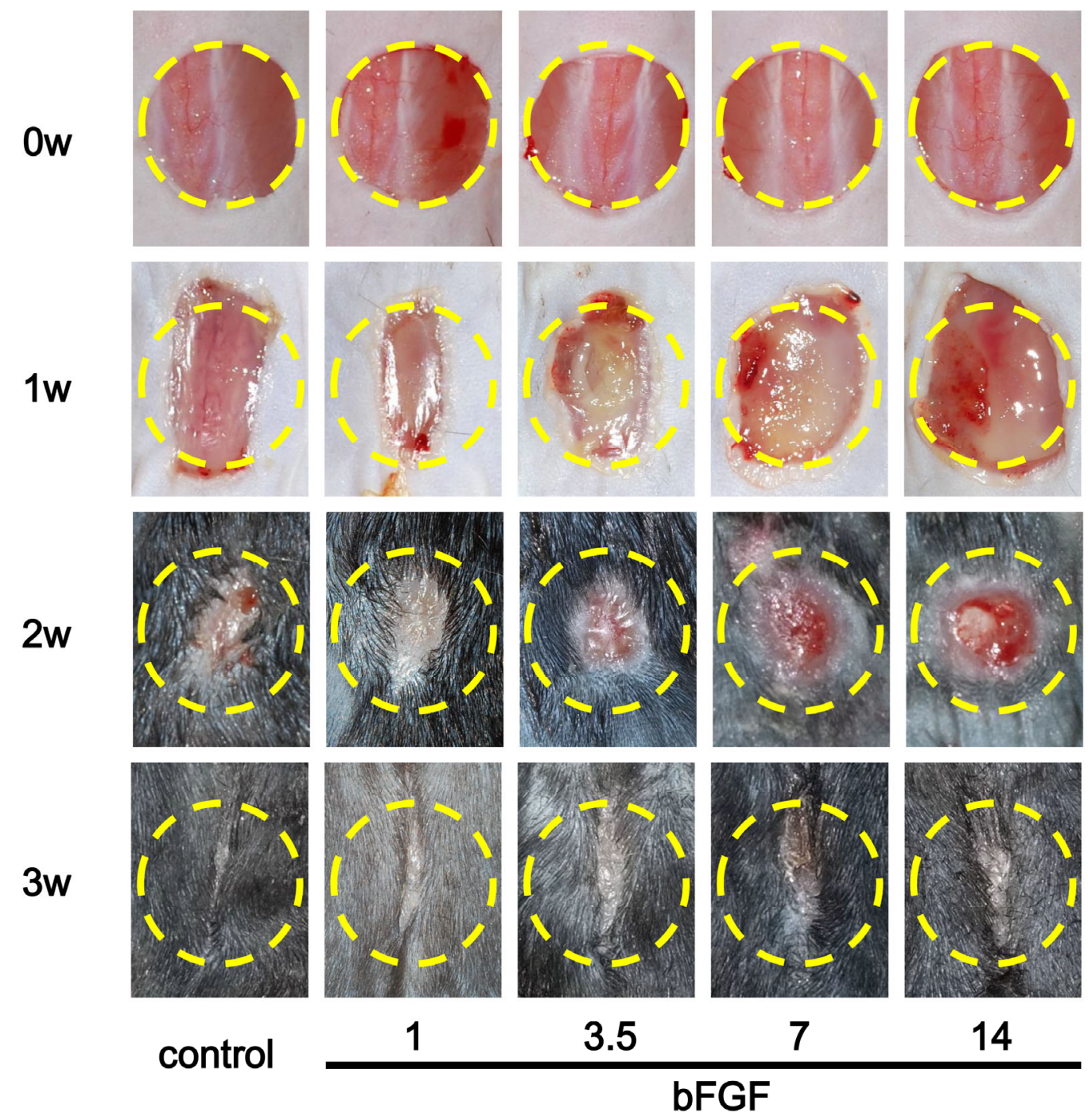

14

Fig.4A 


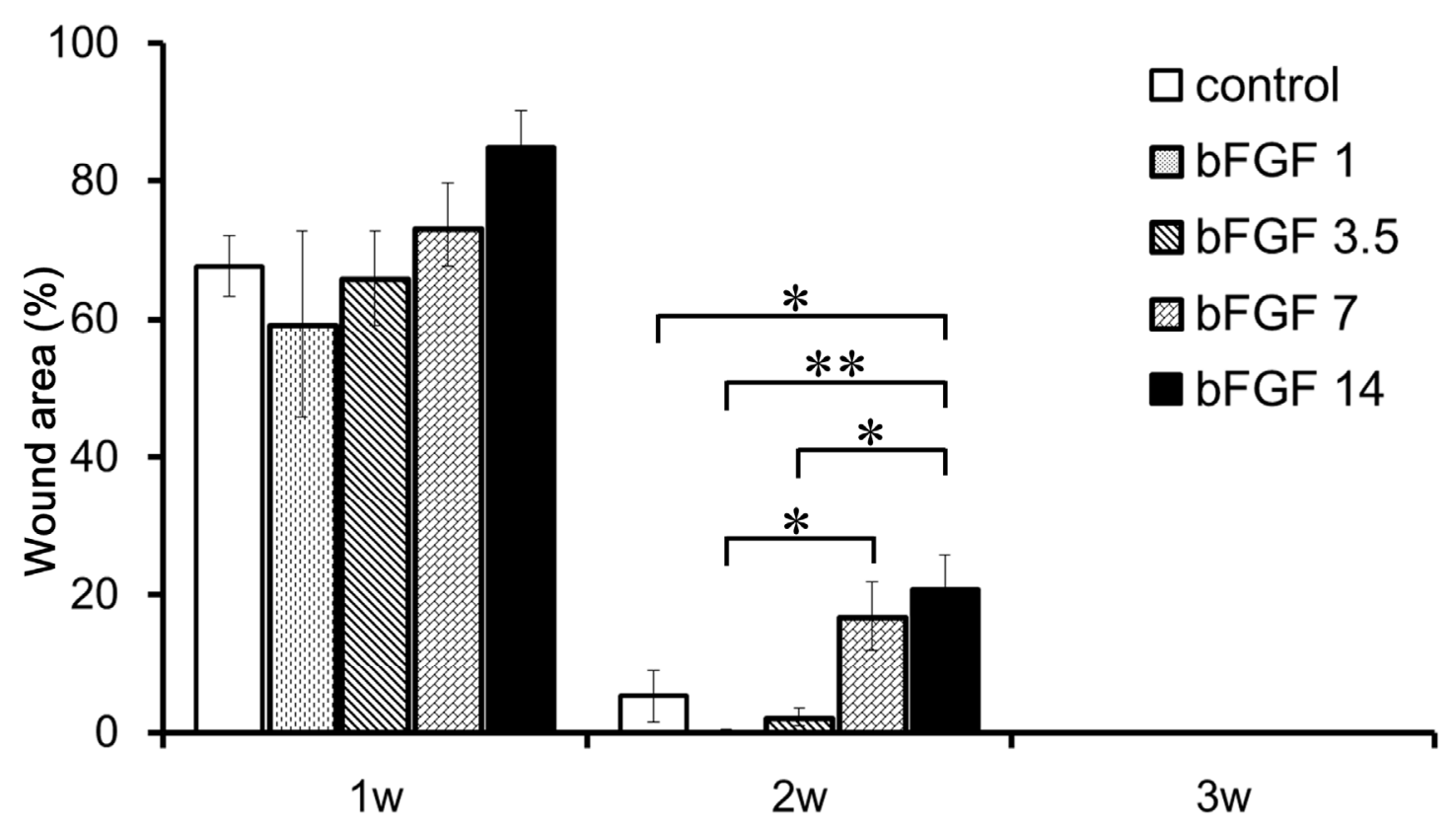

Fig. 4B 


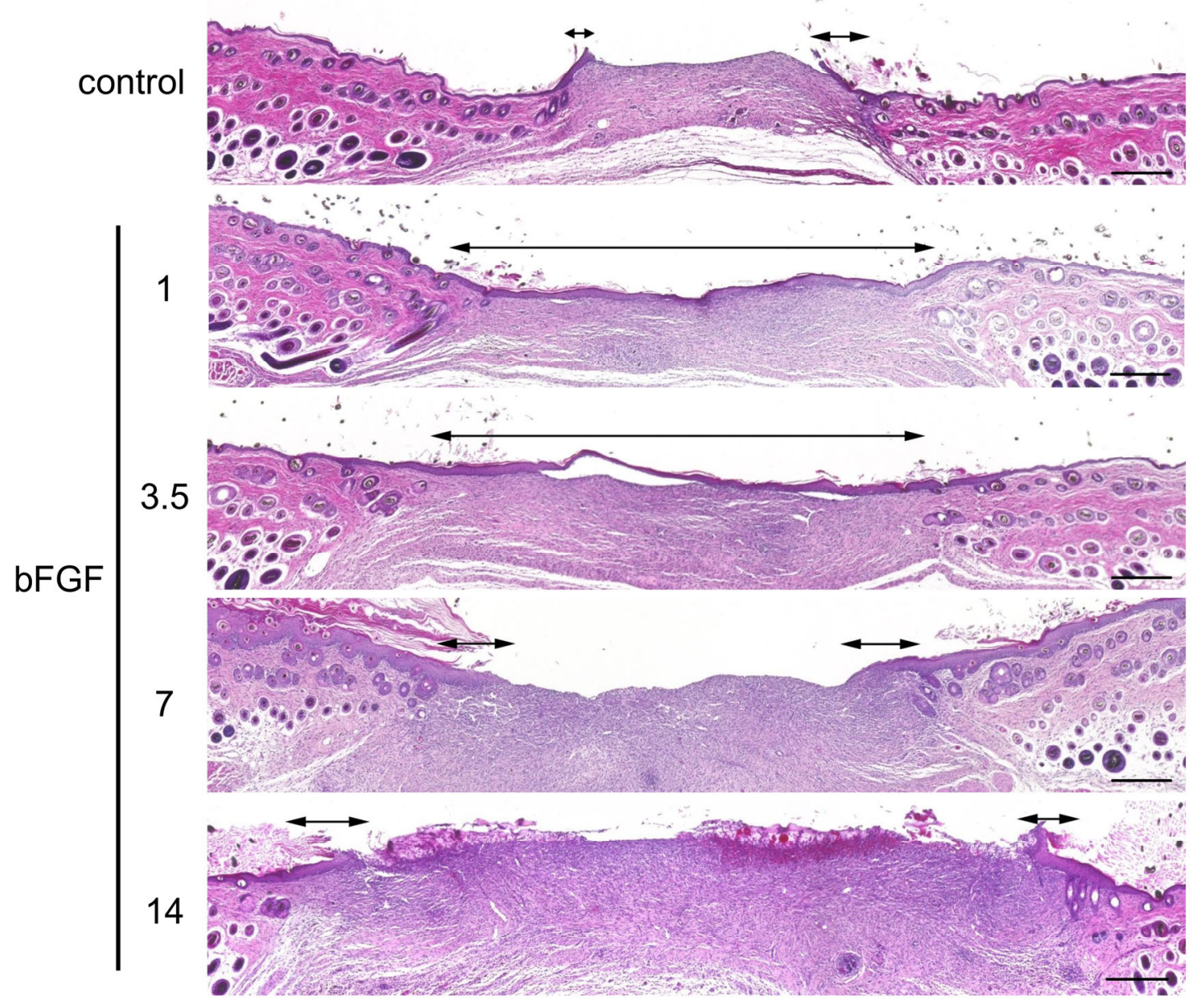

Fig. 5A 


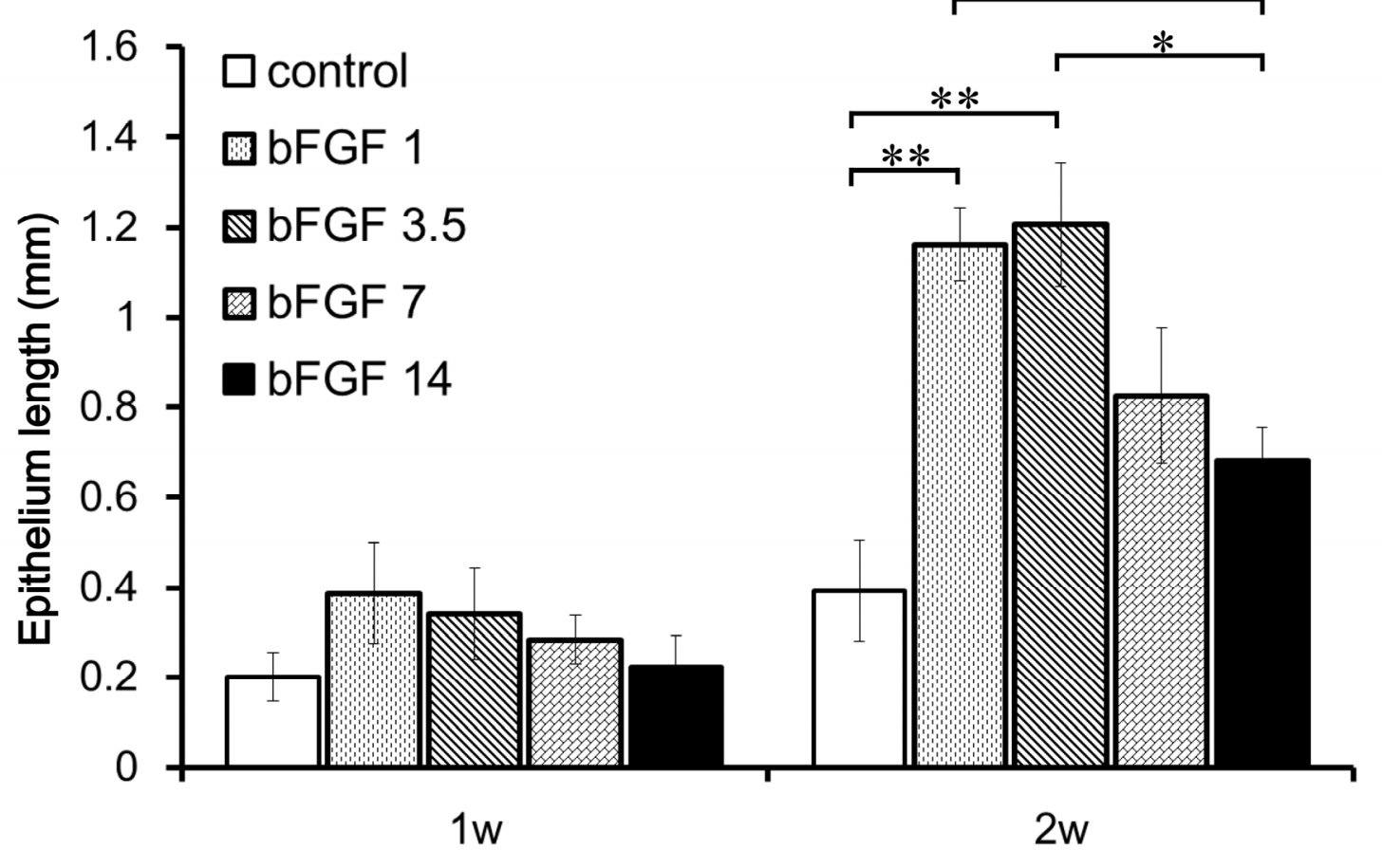

Fig. 5B 


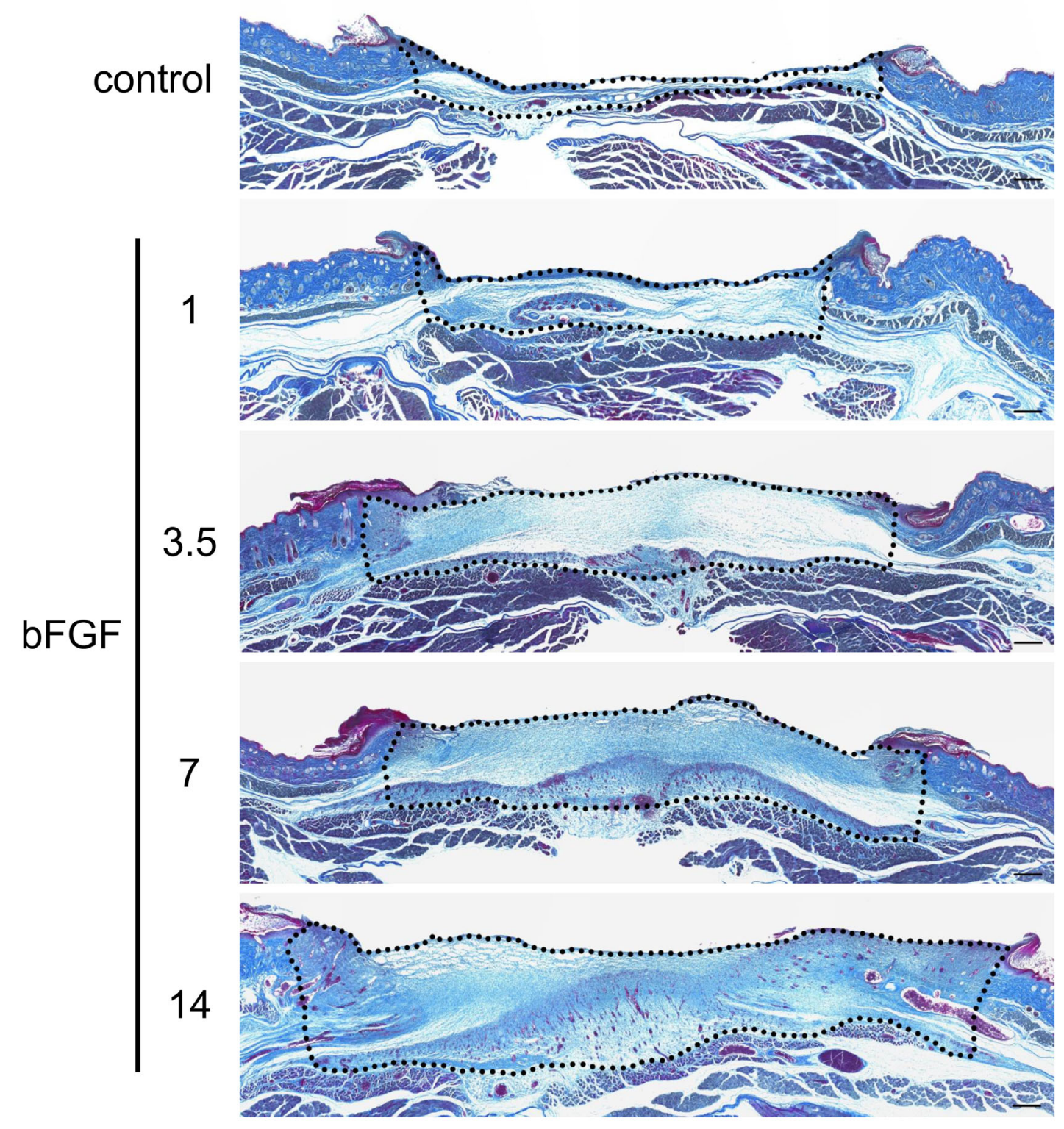

Fig. 6A 


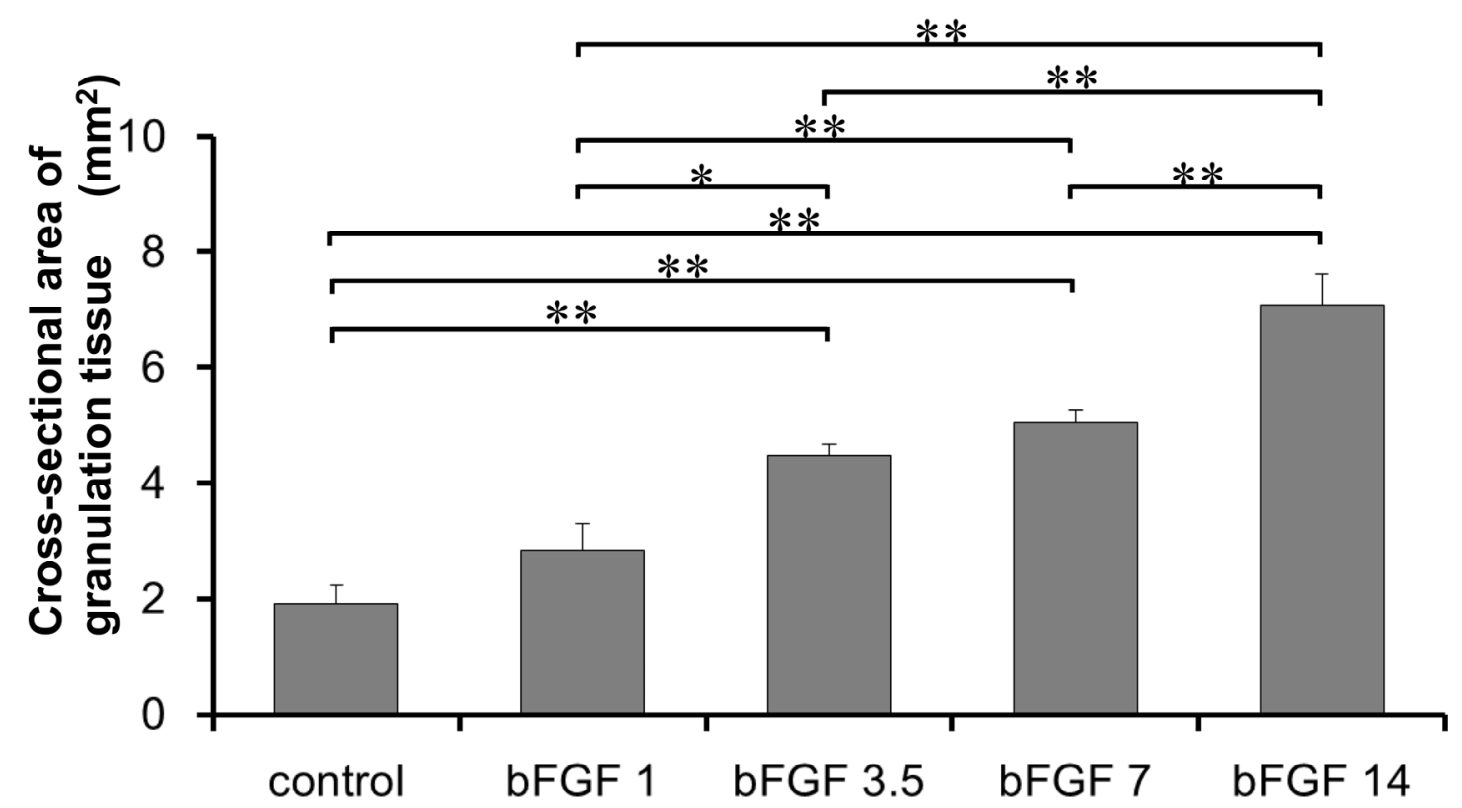

Fig. 6B 


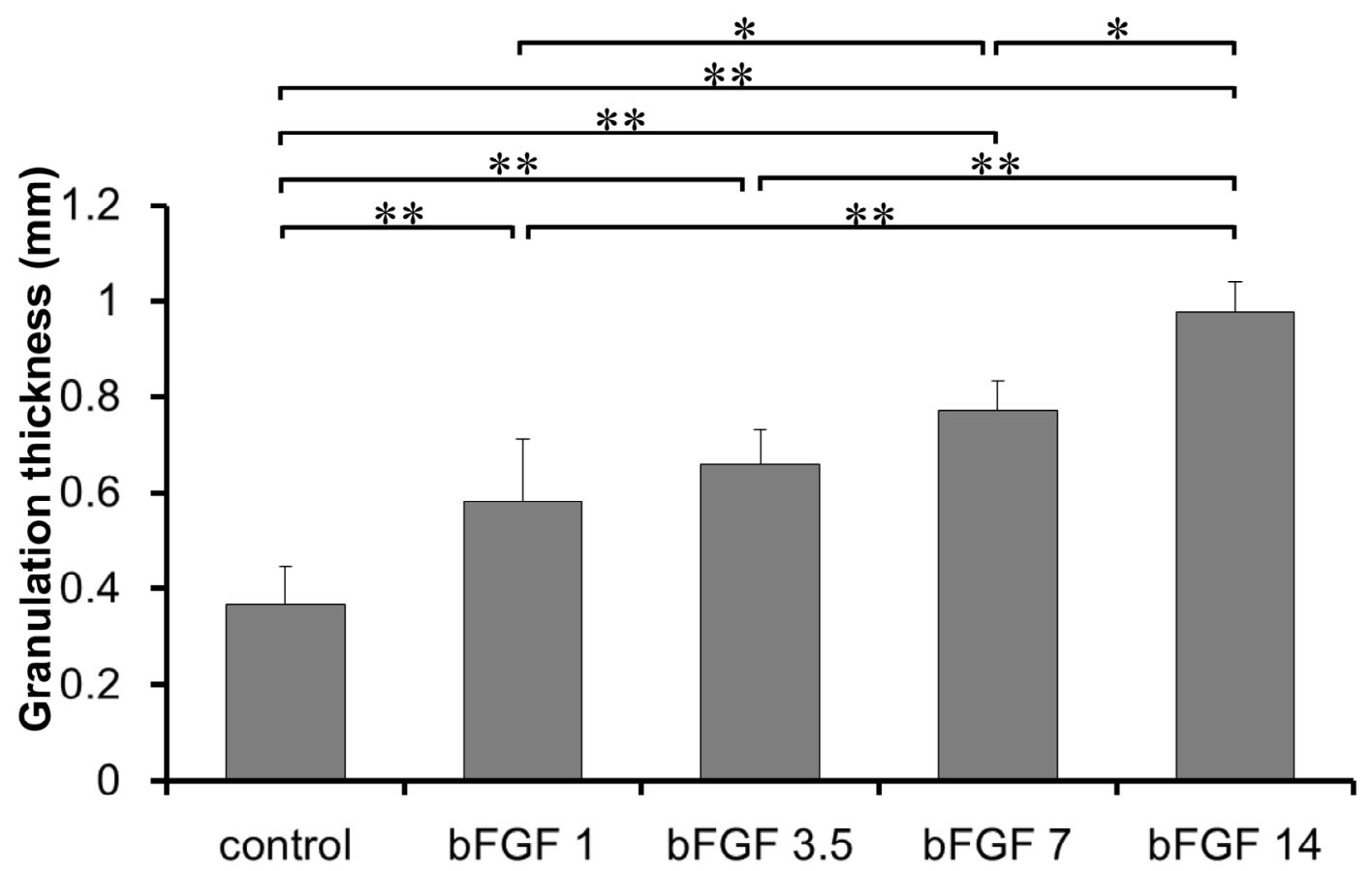

Fig. 6C

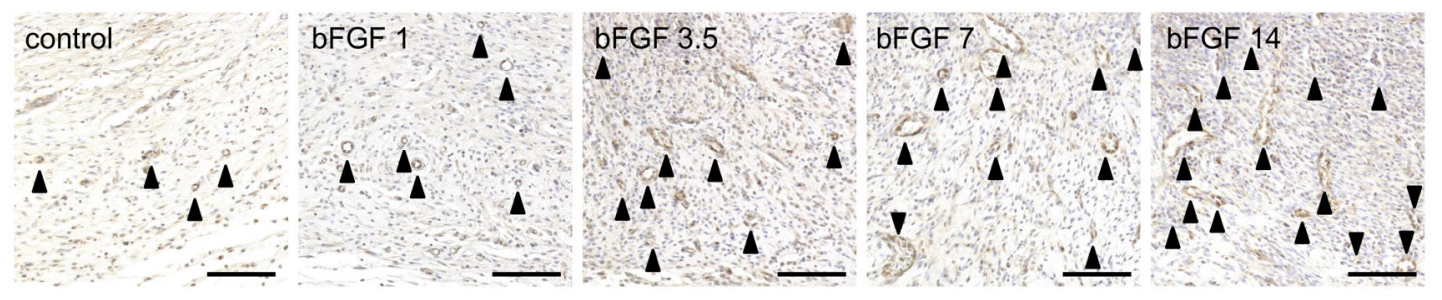

Fig. 7A 


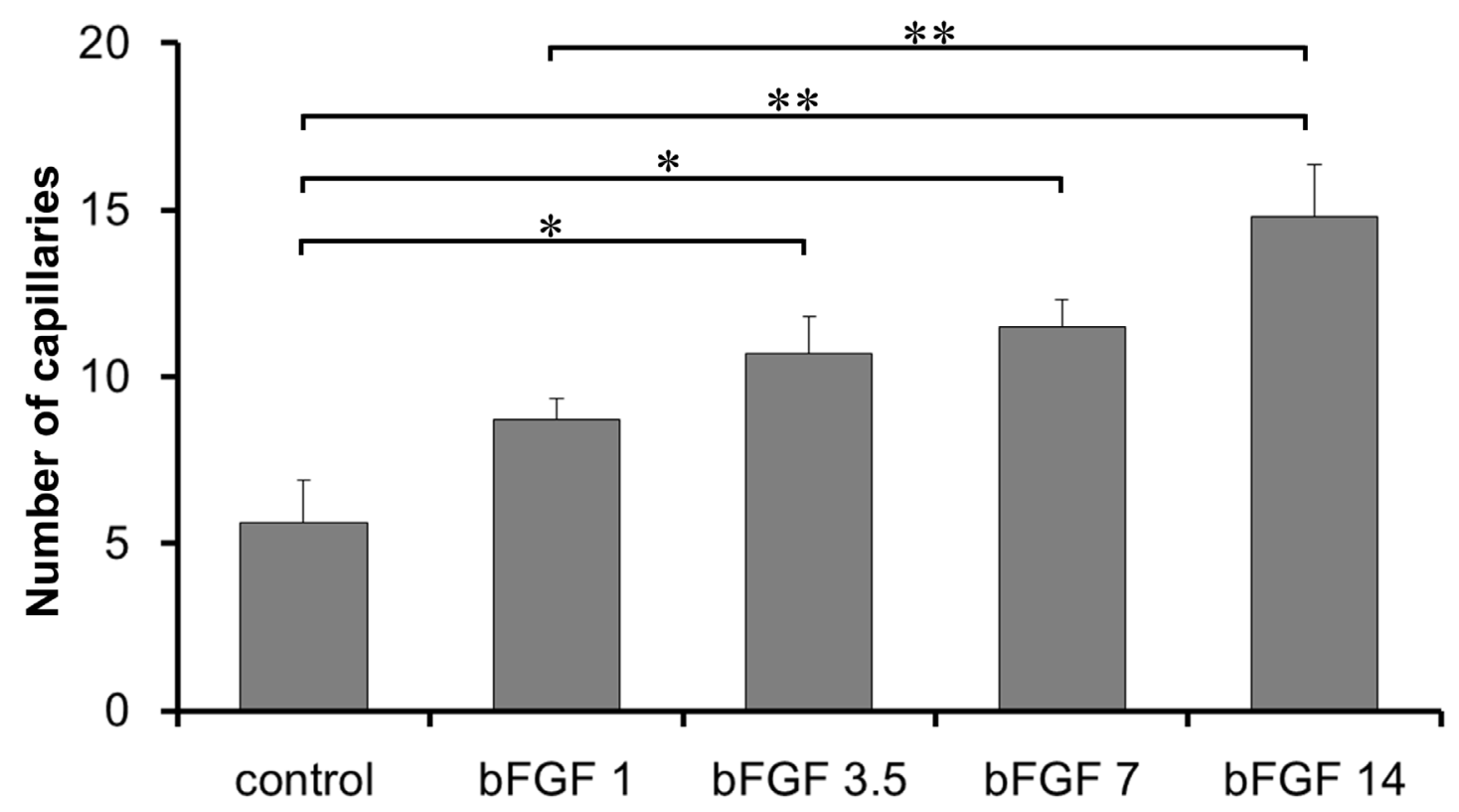

Fig. 7B

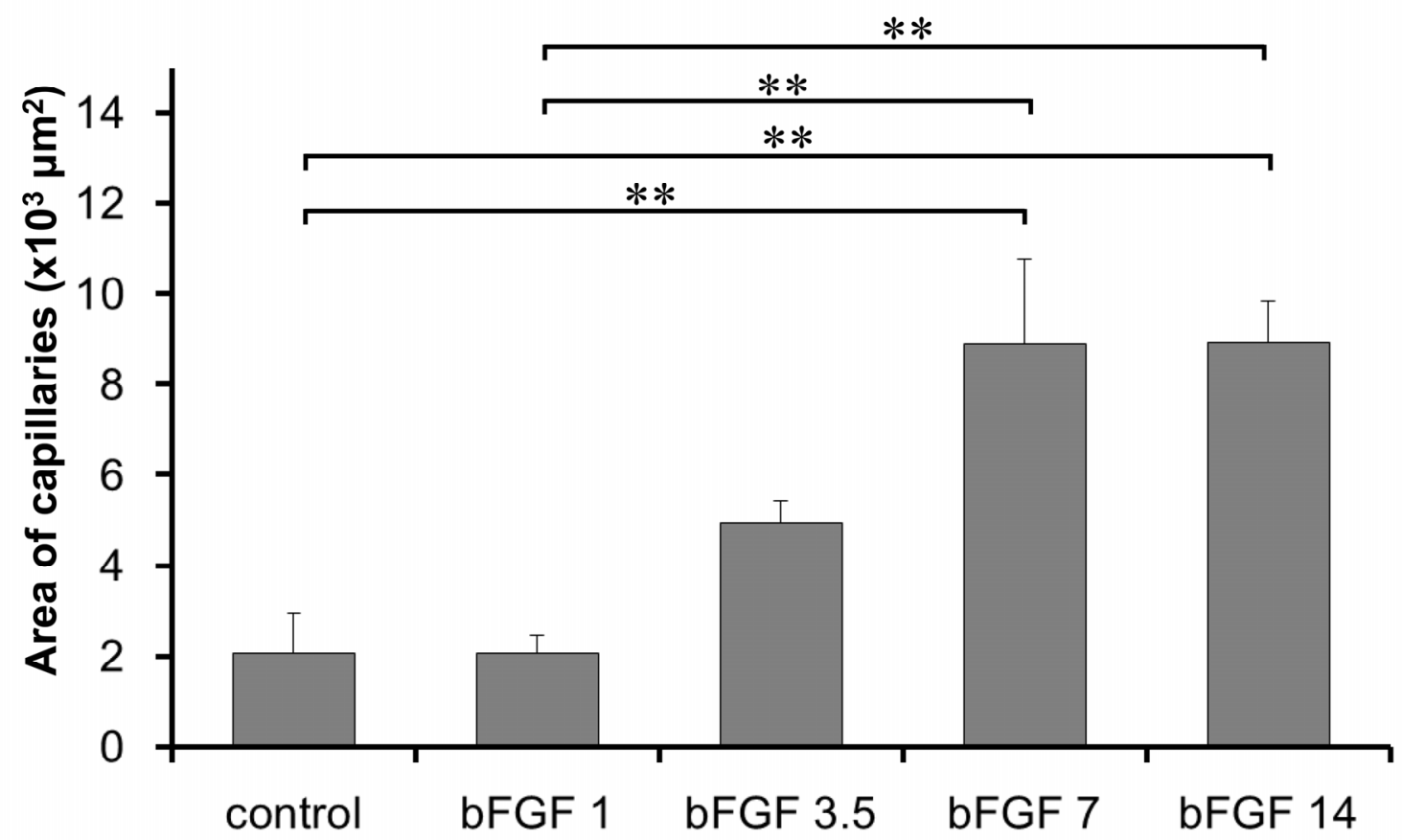

Fig. 7C 